Taskin et al., Afr J Tradit Complement Altern Med. (2013) 10(2):353-355

http://dx.doi.org/10.4314/ajtcam.v10i2.22

\title{
DETERMINATION OF VOLATILE AROMA COMPOUNDS OF GANODERMA LUCIDUM BY GAS CHROMATOGRAPHY MASS SPECTROMETRY (HS-GC/MS)
}

\author{
Hatıra Taşkın $^{1}$, Ebru Kafkas ${ }^{1}$, Özgün Çakıroğlu ${ }^{2}$, Saadet Büyükalaca ${ }^{1}$ \\ ${ }^{1}$ Çukurova University, Faculty of Agriculture, Department of Horticulture, 01330, Adana- \\ Turkey,Çukurova University, Biotechnology Research and Experimental Center, 01330, Adana- \\ Turkey. ${ }^{2}$ Agrosel Agriculture Ltd., Antalya-Turkey \\ *E-mail: htaskin@cu.edu.tr
}

\begin{abstract}
This study was conducted at Horticulture Department of Cukurova University, Adana, Turkey during 2010-2011. Fresh sample of Ganoderma lucidum collected from Mersin province of Turkey was used as material. Volatile aroma compounds were performed by Headspace Gas Chromatography (HS-GC/MS). Alcohols, aldehydes, acids, phenol, L-Alanine, d-Alanine, 3Methyl, 2-Butanamine, 2-Propanamine were determined. 1-Octen-3-ol (Alcohol) and 3-methyl butanal (Aldehyde) were identified as major aroma compounds.
\end{abstract}

Key words: Ganoderma, volatiles, headspace, gas chromatography-mass spectrometry.

\section{Introduction}

Ganoderma lucidum (Curtis) P. Karst. called "mushroom of immortality" and "Reishi" in Turkey is one of the significant and valuable medicinal mushrooms and it is consumed as tea or medicine (Yakupoğlu and Pekșen, 2011). This mushroom is known with different names in different countries in the world such as "Ling Chi, Ling Chih or Ling Zhi' in China and Korean, "Reishi or Mannentake" in Japan (Stamets, 2000) and "Ganoderma" in USA. Medical usage of Ganoderma was indicated by many researchers. It was known to use diseases such as heart diseases, chronic bronchitis, asthma, hypertension, hepatitis, hypercholesterol, allergy and cancer (Hobbs, 1944; Chen and Zhang, 1987). Triterpenes and polysaccharides are two of important chemical compounds in Ganoderma. Polysaccharides, especially beta glucans, stimulate immune system and beta glukans induce production of T cells that against infected cells (Stamets, 2000). Ganoderic acid prevents to coagulation in blood, reduce cholesterol level in blood (Stamets, 2000; Morigawa et al., 1986) and regulate blood pressure, lipid (Stamets, 2000; Kabir et al., 1988) and glucose level (Stamets, 2000; Kimura et al., 1988) of blood. Also it is known as a diuretic, laxative, sedative and tonic (Hobbs, 1944; Liu and Bau, 1980). Volatile flavor compounds from submerged cultured Ganoderma sinense (J.D. Zhao, L.W. Hsu \& X.Q. Zhang) mycelium were analysed by Headspace Gas Chromatography (HS-GC/MS) by Wang et al., (2009). Different types of compunds; including ketones, esters, lactones, alcohols, aethers and hyrodroxybenzenes were identified in $G$. sinense. However, to best our knowledge there is no previous studies on volatile compounds of fresh G. lucidum samples. For this purpose, we aimed to detect volatile compounds of G. lucidum using HS-GC/MS technique.

\section{Material and Methods}

G. lucidum specimens collected from Mediterrenean Region (Mersin province) of Turkey were used in this study. After surface sterilization of this mushroom specimens in sterile bench, small pieces from internal region of fruit body were cut and placed into nutrient medium. Potato Dextrose Agar (PDA: Potato extract: 4 g/l, Dextrose: 20 g/l, Agar: 15 g/l and pH:7.5) was used as nutrient medium. Sterilization of nutrient medium were performed in $121^{\circ} \mathrm{C}$ in $1.2 \mathrm{~atm}$ for 15 min using autoclave. Mycelial growth in all of petri dishes were obtained in 8 days. Then mycelia in each petri dish were divided 6-8 pieces and inoculated to sawdust plastic culture bags (made of high-pressure-resistant plastic) for fruiting body grown. To prepare sawdust culture: firstly oak sawdust material was wet with water to provide $70 \%$ humidity, then added wheat bran, zeolite and mixed. This mixture was filled plastic bags and then sterilized in $121^{\circ} \mathrm{C}$ in $1.2 \mathrm{~atm}$ for $45 \mathrm{~min}$ using autoclave. All of sawdust cultures bags were placed in mushroom growing room has $25^{\circ} \mathrm{C}$ temperature, $80 \%$ humidity and 1000 lux light. Harvested G. lucidum samples were used as fresh for aroma analyses adding $5 \mathrm{~g} \mathrm{NaCl}$ for $50 \mathrm{~g}$ of sample.

Volatile aroma analyses were done at Horticulture Department of Çukurova University, Adana-Turkey. Volatile compounds were analyzed on an HS/GC/MS apparatus equipped with an HP-5 MS (30 m $\times 0.25 \mathrm{~mm} \times 0.25 \mu \mathrm{m})$ fused-silica capillary column. Helium ( $1 \mathrm{ml} / \mathrm{min})$ was used as a carrier gas. The SPME holder, for manual sampling, and fibres used in this study were purchased from Supelco (Bellefonte, PA). The polydimethylsiloxane (PDMS) $100 \mathrm{~mm}$ fibres were used and the fibres conditioned for $1 \mathrm{~h}$ at $240^{\circ} \mathrm{C}$ in the GC injector port before being used, and they were cleaned between analyses to prevent contamination. The injector temperature was $250^{\circ} \mathrm{C}$, set for split less injection. The oven conditions were set to $50^{\circ} \mathrm{C}$ for $1 \mathrm{~min}$ and then the temperature was increased to $200^{\circ} \mathrm{C}$ at a rate of $4^{\circ} \mathrm{C} / \mathrm{min}$. Thermal desorption was allowed for $1.5 \mathrm{~min}$. The detector 
Taskin et al., Afr J Tradit Complement Altern Med. (2013) 10(2):353-355

http://dx.doi.org/10.4314/ajtcam.v10i2.22

temperature was $280^{\circ} \mathrm{C}$. The components were identified by comparison of mass spectra and retention time data complemented with a Wiley, Flavor and NIST GC-MS libraries.

\section{Results and Discussion}

18 aroma compunds were identified in this study and obtained results were given in Table 1. As seen in Table 1, alcohols such as 1-Octen-3-ol, 3-Octanol, 1-Octanol, 2-ethyl-1-Hexanol were detected as the major compounds and consisting of approximately $48.05 \%$ of total aroma. Among the detected alcohols 1-Octen-3-ol was detected as the major one. 1-Octen-3-ol (mushroom, butter, resinous), 3-Octanol (fruity, cod liver oil, citrus, weakly nutty, fungal), 1-Octanol (fruity-flowery, sweet soap, orange, waxy, sweet) 1-Octen-3-one (boiled mushrooms, metallic, fungal, wild mushroom), 3-Octanone (fruity, sweet, musty, floral, lavender, sweet ester), 2-Octen-3-ol and 3-Octanal are the well-known and common aroma compounds (Jong and Birmingham, 1993; Taylor and Linforth, 2010). The identified aldehydes were detected as 3-methyl butanal, 2-Octenal, pentanal, 2,4-Decadienal, 1-Proponal. Among them 3-methyl butanal was detected as the major aldehyde. As for the acids; 1,2Benzenedicarboxylic acid, Hexadecanoic acid, Octadecanoic acid were detected and among them hexadecanoic acid was the major. Hexadecanoic acid is a synonym of palmitic acid and it used to produce soap and cosmetic. 3-Octanone, phenol and other compounds such as d-Alanine, L-Alanine, 3-Methyl, 2-Butanamine, 2-Propanamine were detected also. Phenolic compounds are found as major antioxidant componets in mushrooms (Tsai et al., 2009; Lee et al., 2010).

In addition to Benzeneacetaldehyde, Cyclooctene, Formic acid, Benzothiazole 2,4-Decadienal, 2,6-di-butyl-2,5cyclohexadiene-1, Phythalic acid, Ethanol, 2-Heptanamine, Alanine, Cyclopentane, Butanal, Eicosane, Squalene, Iron, Tetradecane, Nonane, Decanal, 2H-Pyran-2-One, Oxirane, n-Hexylmethylamine, 2-Methylaminoethanol, 1,2-Ethanediamine, Cyclohexadecane, Heptadecene were detected trace amount in G. lucidum.

Table 1: Volatile composition of Ganoderma lucidium by HS-GC/MS.

\begin{tabular}{lll}
\hline R.T & Compound name & Area \% \\
\hline Alcohols & 1-Octen-3-ol & 34.67 \\
7.35 & 3-Octanone & 14.41 \\
7.50 & 3-Octanol & 9.72 \\
7.72 & 2-ethyl 1-Hexanol & 3.08 \\
8.61 & 1-Octanol & 0.58 \\
9.76 & 3-methyl Butanal & 18.87 \\
\hline Aldehydes & 2-Octenal & 0.85 \\
6.40 & 1-Proponal & 0.28 \\
9.41 & Pentanal & 0.23 \\
1.45 & 2,4-Decadienal & 0.07 \\
2.48 & Hexadecanoic acid & \\
16.22 & Octadecanoic acid & 2.38 \\
\hline Acids & 1,2-Benzenedicarboxylic acid & 0.96 \\
32.28 & & 0.16 \\
35.42 & Phenol & 4.34 \\
30.47 & L-Alanine & 0.21 \\
\hline Phenol 2.20 & d-Alanine & 0.10 \\
\hline Other compounds & 3-Methyl, 2-Butanamine & 0.04 \\
1.89 & 2-Propanamine & 0.02 \\
1.90 & Other compounds & 9.03 \\
3.20 & &
\end{tabular}

RT: Retention time

28 volatile flavor compounds were identified in G. sinense by Liu et al., (2009). Also 26 volatile compounds were detected in $G$. sinense by Wang et al., (2009). In both of these studies, ketones, alcohols and lactones were found as main compounds. In a study conducted by Chen et al., (2010), 58 compunds were determined in G. lucidum mycelia and 1-octen-3-ol, ethanol, hexanal, 1hexanol, sesquirosefuran, 3-octanol, 3-octanone were found as main volatile flavor compounds. In all of these studies, mycelia were used to determine volatile aroma compounds. Presented in this study, the fresh mushroom samples collected from nature and cultured were used for aroma analyses. Alcohols and aldehydes were identified as main volatile aroma compounds. 
Taskin et al., Afr J Tradit Complement Altern Med. (2013) 10(2):353-355

http://dx.doi.org/10.4314/ajtcam.v10i2.22

\section{Acknowledgments}

The authors want to special thanks to the Çukurova University Scientific Research Projects Coordinating Office (ÇÜBAP-ZF2010BAP27) for aroma analyses.

\section{References}

1. Chen, K. and Zhang, W. (1987). Advances in anti-aging herbal medicines in China. Advances in anti-aging herbal medicines in China. Abstracts of Chinese Medicine, 1:309-330.

2. Chen, Z., Yang, Z. and Gu, Z. (2010). Determination of Volatile Flavor Compounds in Ganoderma lucidum by HSSPME-GC-MS. http://en.cnki.com.cn/Article_en/ CJFDTOTAL-SPYK201002043.htm.

3. Hobbs, C. (1944). Medicinal Mushrooms. Botanica Press. Summertown, Tennessee.

4. Jong, S.C. and Birmingham, J.M. (1993). Mushrooms as a source of natural flavor and aroma compounds. In: Mushroom biology and mushroom production (Chang ST, Buswell JA, Chiu SW, eds). Chinese University Press, Pekin, pp. 345-366.

5. Kabir, Y., Kimura, S. and Tamura, T. (1988). Dietary effect of Ganoderma lucidum mushroom on blood pressure and lipid levels in spontaneously hypertensive rats (SHR). J Nutr Sci Vitaminol, 34: 433-438.

Kimura, Y., Okuda, H. and Arichi, S. (1988). Effects of the extracts of Ganoderma lucidum on blood glucose level in rats. Planta Med, 54(4): 290-4.

Lee, H., Kalaras, M. and Beelman, R. (2010). Total Nutraceutical Solutions Funded Study Reveals Potent Antioxidant Food Value of Mushrooms. Annual IFT Meeting.

Liu, B. and Bau, Y.S. (1980). Fungi Pharmacopoeia. Sinoko Co., Oakland, California, 170-172.

Liu, G.Q., Wang, X.L. and Jin, X.C. (2009). Head-Space Gas Chromatographic Analysis for the Volatile Flavor Compounds from Submerged Culture Broth of Ganoderma sinense (a Medicinal Fungus). $3^{\text {rd }}$ International Conference on Bioinformatics and Biomedical Engineering, 1-3.

10. Morigawa, A., Kitabatake, K., Fujimoto, Y. and Ikekawa, N. (1986). Angiotensin converting enzyme-inhibiting triterpenes from Ganoderma lucidum. Chemical and Pharmaceutical Bulletin, 34(7): 3025-3028.

11. Stamets, P. (2000). Growing Gourmet and Medicinal Mushrooms. Third Edition. Ten Speed Press. Berkeley, Toronto.

12. Taylor, A.J. and Linforth, R.S.T. (2010). Mushroom. In: Food Flavour Technology, Second Edition 2010. Wiley Blackeell, pp. 161.

13. Tsai, S.Y., Huan, S.J., Lo, S.H., Wu, T.P., Lian, P.Y. and Mau, J.L. (2009). Flavour components and antioxidant properties of several cultivated mushrooms. Food Chemistry, 113:578-584.

14. Yakupoğlu, G. And Pekşen, A. (2011). Çay Atığından Hazırlanan Farklı Kompost ve Partikül Büyüklüğünün Ganoderma lucidum Mantarının Verimi ve Bazı Morfolojik Özellikleri Üzerine Etkisi. Ekoloji, 20(78): 41-47.

15. Wang, X.L., Han, W.J. and Zhou, G.Y. (2009). Analysis of Volatile Flavor Compounds in Submerged Cultured Ganoderma Sinense Mycelium by Headspace Gas Chromatography. 2nd International Conference on Biomedical Engineering and Informatics, 1-4. 